\title{
Leaf Chlorophyll LevelsInfluence Carbon Isotope Discrimination in Soybean and Maize
}

\author{
Madhavan Soundararajan
}

\begin{abstract}
A significant positive correlation between carbon isotope ratio $(\delta 13 \mathrm{C}, \%)$ and total chlorophyll concentration [ChI] was observed in field-grown soybean (Glycine max $\mathrm{L}$.) and Maize ( Zea mays, L.) leaves with varying Chl levels. Leaf $\delta 13 \mathrm{C}$ values became less negative by up to $4.5 \%$ with increasing $\mathrm{Chl}$ levels from 40 to $500 \mu \mathrm{mol} \mathrm{m-2}$ in soybean whereas in maize, the same values became more negative $(\sim 1 \%)$. The trend towards decreased leaf carbon isotope fractionation with increased $\mathrm{Chl}$ levels in soybean and maize suggests an enhanced carboxylation capacity in these leaves. Soybean leaves showed a linear increase in GAPDH activity with increase in leaf [Chl] suggesting an enhanced Ribulose -1,5- bisphosphate (RuBP) pool size. Levels of Ribulosebisphosphate carboxylase (Rubisco) also increased in concert with leaf $\mathrm{Chl}$ levels. Less negative $\delta^{13} \mathrm{C}$ values in these leaves with increasing [Chl] is thus due to an enhanced carboxylation capacity, resulting from a larger RuBP pool size and increased Rubisco levels. Gas exchange studies of these leaves also indicated a correlation between $\mathrm{Chl}$ content and net photosynthetic rate. Results from this study demonstrate that leaf $\mathrm{Chl}$ provides a major molecular basis influencing leaf carbon isotope discrimination by regulating carboxylation strength.
\end{abstract}

Index Terms-Carbon isotope discrimination, chlorophyll, photosynthesis, ribulose 1, 5-bisphosphate carboxylase/oxygenase.

\section{INTRODUCTION}

Carbon isotope composition of whole plants and plant organs provides an integrated, long-term view of carbon assimilation. In terrestrial $\mathrm{C}_{3}$ plants, isotope fractionation can be described by the equation

$$
\Delta \delta=a+\left[(b-a) P_{\mathrm{int}} / P_{a t m}\right]-d
$$

where $\Delta \delta$ is $\delta^{13} \mathrm{C}_{\text {[source] }}-\delta^{13} \mathrm{C}_{\text {[leaf] }}, a$ is the discrimination due to diffusion $(4.4 \% 0), b$ is the discrimination by Rubisco $(30 \%), \underline{\mathrm{P}}_{\text {int }}$ is the internal partial pressure of $\mathrm{CO}_{2}$ inside the leaf airspace, and $\mathrm{P}_{a t m}$ is the partial pressure of $\mathrm{CO}_{2}$ in the atmosphere [1], [2]. The term $d$ is expected to include contributions from respiration, isotopic changes due to transport of photosynthates and a variety of other factors. In terrestrial $\mathrm{C} 4$ plants, isotope fractionation can best be described by the following equation:

$\Delta=\mathrm{a}+\left(\mathrm{b}_{4}+\phi\left(\mathrm{b}_{3}-\mathrm{s}\right)-\mathrm{a}\right) \mathrm{Pi} / \mathrm{Pa}$, where $\mathrm{b}_{4}$ represents combined fractionation of phosphoenolpyruvate carboxylase $(2.2 \%)$ and the preceding isotope equilibrium during dissolution of $\mathrm{CO}_{2}$ and conversion to bicarbonate $(-5.7 \%$ ).

Manuscript received April 20, 2012; revised May 29, 2012

M. Soundararajan is with the Department of Biochemistry, University of Nebraska, Lincoln, NE 68588-0664, USA. (Phone: 402-472-9802; fax: 402-472-7842; e-mail: msoundararajan1@unl.edu).
Several physical factors have been shown to influence the integrated balance of stomatal conductance and carboxylation, and thus affect isotopic discrimination in plants [3], [4].

A molecular basis for the variation in foliar $\delta^{13} \mathrm{C}$ values of groundnut genotypes due to variation in Rubisco levels has been reported [6]. Leaf $\mathrm{Chl}$ content has received very little attention as a significant molecular basis for variation in leaf carbon isotope discrimination in plants. Sweetclover mutants with temperature-sensitive expression of Chl content showed a decrease in leaf carbon isotope discrimination with increasing Chl levels [7]. Total leaf Chl content has also been reported to bepositively correlated with foliar $\delta^{13} \mathrm{C}$ in Juniperus, [8].

A variety of controls regulate leaf photosynthesis[8]. Manipulations resulting in the reduction of leaf $\mathrm{Chl}$ content induced true limitations in the rate of photosynthesis [9]. Photosynthetic rates have been positively correlated with $\mathrm{Chl}$ content in leaves of field-grown soybean [10] and peas [11]. A negative correlation between $\mathrm{Chl}$ content and photosynthetic rate has also been reported for certain cowpea mutants [12], and in certain Chl-deficient soybean isolines [13]. In this study we present evidence supporting a strong positive relationship between leaf $\mathrm{Chl}$ content and carbon assimilation, as indicated by both leaf carbon isotope discrimination and other physiological processes in field-grown soybean plants.

\section{Materials And Methods}

\section{A. Plants}

Various lines of soybean (Glycine max L.cv. Hobbit) plants were grown in test plots at the UNL Field Research and Development Station, Institute of Agriculture and Natural Resources, Mead, NE. Soybean plants grown at the Mead facility received modest amounts of supplemental nitrogen. Maize (Pioneer brand hybrid 3379) plants were grown in pots $30 \mathrm{~cm}$ diameter by $30 \mathrm{~cm}$ depth, in the greenhouse. Plants in all pots were maintained in a well watered state. In order to cause variation in Chlorphyll concentration plants were subjected to different $\mathrm{N}$ treatments $\left(0,50,100,125,150,175,200,225,250\right.$ and $\left.275 \mathrm{~kg} \mathrm{~N} \mathrm{ha}^{-1}\right)$.

\section{B. Chl Determinations}

Fully developed, non-senescing leaves from the third or fourth nodes of approximately 10 week old soybean plants, were selected by Chl content. For maize plants, ear leaves were samples for their $\mathrm{Chl}$ content. Leaf Chl determinations were made using a Minolta SPAD-502 meter . Rather than attempt to replicate individual measurements, individual 
plants of various soybean lines and maize ear leaves were selected to provide a large number of SPAD-502 meter readings with a wide range of values. The meter readings were converted to total leaf $\mathrm{Chl}$ content $\left(\mu \mathrm{mol} \mathrm{m}{ }^{-2}\right)$ using an equation obtained from regression analysis of the raw meter readings and conventional $\mathrm{Chl}$ assays [14].

$$
\text { Chl Concentration }=10^{\text {(Meter Reading }^{0.265}}
$$

\section{Carbon Isotope Fractionation}

Carbon isotope ratio measurements were made following published procedures [4].Briefly, leaves with various Chl levels were harvested from soybean plants grown during the summer of 1994 in the East Campus field nursery plots, and dried in an oven for $48 \mathrm{~h}$ at $60^{\circ} \mathrm{C}$. The leaf material was ground to a fine powder. A subsample of this leaf powder (2-3 mg) was analyzed for carbon isotope ratio using an elemental analyzer (Heraeus, CHN-O Rapid) interfaced with an automated trapping box system and a Finnigan Delta-S isotope ratio mass spectrometer. The isotope ratio of each sample was determined by comparison with a previously calibrated working standard with a known $\delta^{13} \mathrm{C}$ value (precision $\pm 0.2 \%$ ) relative to PDB ( Pee Dee Belemnite international standard). The ${ }^{13} \mathrm{C}$ content of $\mathrm{CO}_{2}$ is given as an isotope ratio, $\underline{\mathrm{R}}$,

$$
R=\left[{ }^{13} \mathrm{CO}_{2}\right] /\left[{ }^{12} \mathrm{CO}_{2}\right]
$$

and ${ }^{13} \mathrm{C}$ is given by,

$$
\delta^{13} \mathrm{C}=1000\left[\left(R_{\text {sample }} / R_{\text {standard }}\right)-1\right]
$$

\section{Quantitative Relationship Between [Chl] and Carbon Isotope Discrimination}

The concentration of $\mathrm{Chl}$ should be related to $\delta^{1} \mathrm{C}$ through the Beer-Lambert law: $I_{f}=I_{i} e^{-\alpha b C}$ where $I_{f}$ is the intensity of light transmitted through the sample, $I_{i}$ is the initial intensity of light, $\alpha$ is the absorption, $b$ is the sample thickness, and $\mathrm{C}$ is the concentration of the light-absorbing compound. The fraction of light absorbed is then equal to the quantity $1-I_{f} / I_{i}=1-e^{\alpha b C}$. The fraction of light absorbed by $\mathrm{Chl}$ should be proportional to the metabolic energy produced. The relationship between $\delta^{1} \quad \mathrm{C}$ and [Chl] can be quantitatively described by the following function:

$$
\delta^{13} \mathrm{C}=\Delta \delta^{13} \mathrm{C}\left(1-e^{-\mathrm{A}_{\mathrm{L}} \frac{[\mathrm{Chl}]}{\mathrm{Ch}_{\max }-[\mathrm{Chl}]}}\right)+\delta^{13} \mathrm{C}_{0}
$$

In this equation $\Delta \quad{ }^{1} \mathrm{C}$ is a constant describing the total change in $\delta^{1} \quad \mathrm{C}$ and $\delta^{1} \quad \mathrm{C}_{0}$ is a constant equal to the $\delta^{1} \quad \mathrm{C}$ value extrapolated to the complete absence of $\mathrm{Chl}$. $\mathrm{A}_{\mathrm{L}}$, the leaf absorption constant, includes at least two factors: an extinction constant for the relative amount of $\mathrm{Chl}$ in the leaf and a leaf thickness constant. The constant, $\mathrm{Chl}_{\max }$ is the maximum observed $\mathrm{Chl}$ concentration for the plant.

\section{E. Gas Exchange}

A LI-COR LI-6200 portable photosynthesis system with a $1 \mathrm{~L}$ leaf cuvette was used to make gas exchange measurements on a subset of the leaves used for carbon isotope analysis. All gas exchange measurements were made at a PPFD of $1800-2100 \mu \mathrm{mol} \mathrm{m} \mathrm{m}^{-2} \mathrm{~s}^{-1}$, an RH of $50-60 \%$, and a temperature around $27-29^{\circ} \mathrm{C}$. The initial $\mathrm{CO}_{2}$ concentration in the leaf chamber was between $290-330 \mathrm{~mm}^{-3}$ $\mathrm{CO}_{2} \mathrm{dm}^{3}$ air, as detected by the IRGA of the LI 6200 system. At least 6 measurements were made for each determination. Data for $A, \mathrm{P}_{\text {int }}, \mathrm{g}, \mathrm{RH}$ and leaf temperature were obtained simultaneously.

\section{F. Chloroplast GAPDH Assay}

Soybean plants (about 4 to 6 weeks old) grown during the summer on the Mead field nursery plots, Mead, NE were used for NADPH-GAPDH activity measurements. Activity was measured using the method of Price et al. (15) with minor variations. GAP oxidation was monitored spectrophotometrically by following the rate of NADPH formation $\left(340 \mathrm{~nm}, 25^{\circ} \mathrm{C}\right)$. Each sample was prepared from 3 or 5 leaf punches $(1 \mathrm{cmdiameter}$ each)ground in $0.125 \mathrm{~cm} 3$ grinding buffer per punch. The grinding buffer consisted of $100 \mathrm{~mol} \quad \mathrm{~m}^{-3} \quad$ Epps (N-[2-hydroxyethyl] -piperazine-N'-[3-propanesulfonic acid])- $\mathrm{NaOH}, \mathrm{pH}$ 8.0, 2 mol m${ }^{-3}$ Na2EDTA, $10 \mathrm{~mol} \mathrm{~m}^{-3}$ DTT, $10 \mathrm{Kg} \mathrm{m}^{-3}$ (w/v) insoluble PVP, $10 \mathrm{Kg} \mathrm{m}^{-3}(\mathrm{w} / \mathrm{v})$ casein, $20 \mathrm{~mol} \mathrm{~m}^{-3}$ Na-ascorbate, $1 \mathrm{~mol} \mathrm{~m}^{-3} \mathrm{Na}$-diethyldithio- carbamate, $20 \mathrm{~mol}$ $\mathrm{m}^{-3} \mathrm{MgSO}_{4}, 20 \mathrm{~mol} \mathrm{~m}^{-3} \mathrm{NaHCO}_{3}$ and $20 \mathrm{~mol} \mathrm{~m}^{-3} \mathrm{~K}_{2} \mathrm{HPO}_{4}$. PMSF was added to a final concentration of $0.1 \mathrm{~mol} \mathrm{~m}^{-3}$ just before grinding. The homogenate was centrifuged for $10 \mathrm{~min}$ at $10,000 \mathrm{x} \mathrm{g}$ in a Sorvall MV 12 microcentrifuge $\left(4^{\circ} \mathrm{C}\right)$ and the supernatant fluid assayed for GAPDH activity. Each assay contained, in $1.1 \mathrm{~cm}^{3}, 50 \mathrm{~mol} \mathrm{~m}-3$ Bicine- $\mathrm{NaOH}, \mathrm{pH}$ 8.0, $5 \mathrm{~mol} \mathrm{~m}^{-3} \mathrm{MgCl}_{2}, 1 \mathrm{~mol} \mathrm{~m}^{-3}$ EDTA, $5 \mathrm{~mol} \mathrm{~m}^{-3} \mathrm{DTT}, 12$ mol $\mathrm{m}^{-3} \mathrm{NaCl}, \quad 0.2 \mathrm{~mol} \mathrm{~m}^{-3}$ NADP, 180 units of triose-phosphate isomerase (Baker's yeast, Type I) and 50 $\mathrm{mm}^{3}$ of leaf extract. The reaction was started by the addition of DHAP ( $2 \mathrm{~mol} \mathrm{~m}-3$ final concentration). After measuring the rate for $3 \mathrm{~min}, 10 \mathrm{~mol} \mathrm{~m}^{-3} \mathrm{Na}_{2} \mathrm{HAsO}_{3}$ (final concentration) was added to the reaction mixture and the new rate was measured for an additional $3 \mathrm{~min}$. The rate for chloroplast GAPDH activity was determined by subtracting the rate in the absence of arsenate (NADP-dependent cytoplasmic GAPDH) from the rate in the presence of arsenate.

\section{G. Rubisco Levels Determination}

Leaf extracts used for GAPDH assays served as the source for the determination of Rubisco levels by an indirect, sandwich enzyme immunolinkedimmunosorbent assay (ELISA). The procedure of Harlow and Lane (1988) for a 2 antibody sandwich immunoassay was used with some variations. High IgG binding capacity polystyrene 96 well microtiter plates were used for all assays. The volume of all additions of antibodies or antigens added was $50 \mathrm{~mm}^{3}$ per well while the volume of wash or blocking solutions added was $300 \mathrm{~mm}^{3}$ per well. Anti-Rubisco polyclonal antiserum from goat (1:1000) was added to each plate and incubated at $4^{\circ} \mathrm{C}$ for 14 hours. After washing the plates with wash buffer 
(phosphate buffered saline, PBS, containing $2 \mathrm{Kg} \mathrm{m}^{-3}$ tween 20 and $100 \mathrm{~g} \mathrm{~m}^{-3}$ sodium azide) the nonspecific binding sites were blocked by incubating in a solution containing $50 \mathrm{Kg}$ $\mathrm{m}^{-3}$ non-fat dry milk in wash buffer for $2 \mathrm{~h}$ at room temperature. After rinsing the plates with deionized water, antigen diluted in PBS containing $10 \mathrm{Kg} \mathrm{m}^{-3}$ bovine serum albumin was added to the plates and incubated for 2 hours at $37^{\circ}$ C. After extensive washing with the wash buffer, anti-Rubisco polyclonal antiserum from rabbit $(1: 1000)$ was added to the plates and incubated for 2 hours at $37^{\circ} \mathrm{C}$. The plates were extensively washed again with wash buffer. After adding a secondary antibody conjugate, a mouse monoclonal IgG specific for rabbit IgG $\gamma$-chains conjugated to alkaline phosphatase $(1: 1000)$, the plates were sealed and incubated for 24 hours at $4^{\circ} \mathrm{C}$.

Following an extensive washing with the wash buffer, the plates were developed at $20^{\circ} \mathrm{C}$ using para-nitrophenylphosphate as the phosphatase substrate according to the procedure of Harlow and Lane (1988). Absorbance of the para-nitrophenolate ion was measured at $410 \mathrm{~nm}$ using a microtiter plate reader (Dynatech MR4000). Control experiments where one component was left out or rabbit anti-fibrinogen antiserum was substituted for the rabbit anti-Rubisco antiserum gave absorbances that were less than or equal to the blank (no Rubisco) values. For determination of Rubisco levels of unknown samples, absorbances were compared to a standard curve made with known concentrations the original antigen for the goat antibody. All concentrations of known and unknown samples were determined in at least quadruplicate. Plate to plate variation in absorbance required that a standard curve be determined for each microtiterplateLeaf extracts used for GAPDH assays served as the source for the determination of Rubisco levels by an indirect, sandwich enzyme immunolinkedimmunosorbent assay (ELISA). following the procedure of [16].

\section{RESUlTS AND DisCUSSION}

\section{A. Chl Levels and Carbon Isotope Discrimination}

Isotope discrimination decreased with increasing levels of Chl (Figs. 1a and 1b). A difference of about $600 \mu \mathrm{mol}$ of Chl $\mathrm{m}^{-2}$ in leaves resulted in about a $4 \%$ change in carbon isotope discrimination in soybean and about $1 \%$ in maize. Based on the data obtained from several hundred analyses of leaf samples from plants grown in different field plots at various locations, we found that the maximum $\mathrm{Chl}$ concentration in field-grown soybean plants is approximately $750 \mu \mathrm{mol} \mathrm{m}{ }^{-2}$. Fitting our data to equation 5 by nonlinear regression yields the following values for the parameters (value $\pm \mathrm{SE}$ ): $\Delta \delta^{1} \quad \mathrm{C}=4.006 \pm 0.214 \%, \quad \delta^{1} \quad \mathrm{C}_{0}=-31.33 \pm 0.22 \%$, and $\mathrm{A}_{\mathrm{L}}=1.805 \pm 0.241$. The curve generated from the fitting procedures is shown as the line in Figure 1. Carbon isotopic composition of leaves represents a long-term integration of carbon isotope discrimination due to a complex series of physiological and biochemical events. Isotope discrimination, in essence, reflects the balance between $\mathrm{CO}_{2}$ diffusion through the stomata and the chemical uptake of
$\mathrm{CO}_{2}$. In general, $\delta^{13} \mathrm{C}$ values of $\mathrm{C}_{3}$ plants become more negative when carboxylation limits $\mathrm{CO}_{2}$ uptake and less negative under conditions that limit $\mathrm{CO}_{2}$ diffusion [2] and the opposite is true in $\mathrm{C}_{4}$ plants such as maize .This is due to the opposite sign associated with the term $\mathrm{b}$ (discrimination due to carboxylation) in $\mathrm{C}_{4}$ plants (4). The relationship between $\delta^{13} \mathrm{C}$ values and increasing Chlconcentration in this study, parallels results obtained from our earlier studies on growth-chamber grown sweetclover mutants [6]. Less negative leaf $\delta^{13} \mathrm{C}$ values at increased $\mathrm{Chl}$ levels have been reported qualitatively. At leaf [Chl] of $500 \mu \mathrm{mol} \mathrm{m}{ }^{-2}$ or above, it appears that carboxylation ceases to be limiting carbon isotope discrimination.

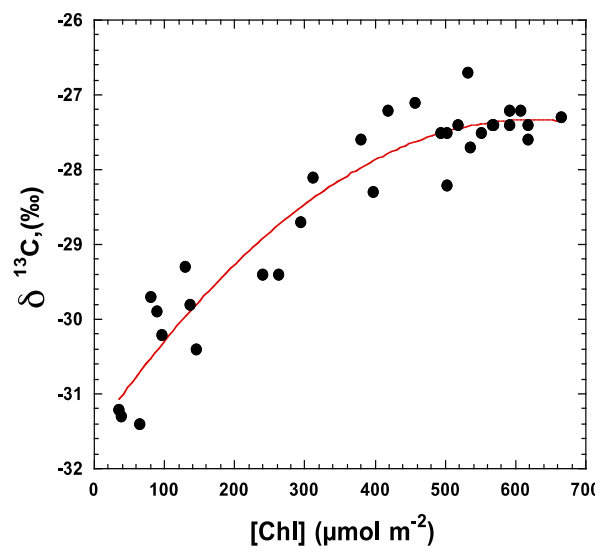

Fig. 1a. Relationship between leaf chlorophyll concentration and $\delta^{13} \mathrm{C}(\% 0)$ in soybean.

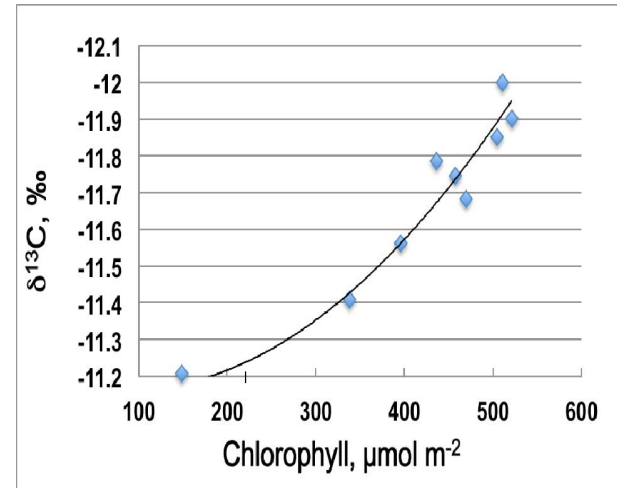

Fig. 1b. Relationship between leaf chlorophyll concentration and $\delta^{13} \mathrm{C}(\%)$ in Maize.

The observed relationship between $\delta^{1} \quad \mathrm{C}$ values and Chl concentrations suggests an efficient photochemical process with increasing levels of Chl. This increased efficiency would result in an increasedRuBP regeneration capacity by increasing the availability of ATP and NADPH.

Light energy availability within a leaf should be governed by the Beer-Lambert law. In this study, we have used this law to quantify the relationship between leaf $\mathrm{Chl}$ concentration and carbon isotope discrimination. However, this relationship of $\delta^{1} \quad \mathrm{C}$ values to $\mathrm{Chl}$ concentration requires several assumptions: uniform $\mathrm{Chl}$ concentration throughout the sample, uniform sample (leaf) thickness, and no light scattering or reflection. To a first approximation, these limitations should either factor out or be the same for all leaves in the same lines (for a more detailed treatment see Markwell et al., 1996). Rearranging equation 5 by separating terms gives the equation: 


$$
\frac{\delta^{13} \mathrm{C}-\delta^{13} \mathrm{C}_{0}}{\Delta \delta^{13} \mathrm{C}}=\left(1-e^{-\mathrm{A}_{\mathrm{L}} \frac{[\mathrm{Chl}]}{\mathrm{Chl}_{\max }-[\mathrm{Chl}]}}\right)
$$

The constant $\mathrm{Chl}_{\max }$ is species-dependent. The quantity $A_{L}$ can be used to determine a quantity of physiological significance, Chl50, the concentration at which the carboxylation limit is half relaxed. In this way, Chl 50 is analogous to an $\mathrm{IC}_{50}$ value. $\mathrm{Chl}_{50}$ is also the concentration of $\mathrm{Chl}$ at which the change in ${ }^{1} \mathrm{C}$ is half maximal. When the change in ${ }^{1} \mathrm{C}$ is half of the total change, the left-hand side of equation 6 equals 0.5 and $[\mathrm{Chl}]=\mathrm{Chl}_{50}$. Equation 6 can then be solved for $\mathrm{Chl}_{50}$. Using the parameters $\mathrm{A}_{\mathrm{L}}$ as 1.805 and $\mathrm{Chl}_{\max }$ as $750 \mathrm{~mol} \mathrm{~m}^{-2}$ from this study, the value for $\mathrm{Chl}_{50}$ is $208 \mu \mathrm{mol} \mathrm{m}^{-2}$. This suggests even under reduced levels such $208 \mu \mathrm{mol} \mathrm{m} \mathrm{m}^{-2}$ of Chl, carbon isotope discrimination in soybean plants is limited more by $\mathrm{CO}_{2}$ diffusion than by carboxylation.

\section{B. Chl Levels and Stromal GAPDH Activity}

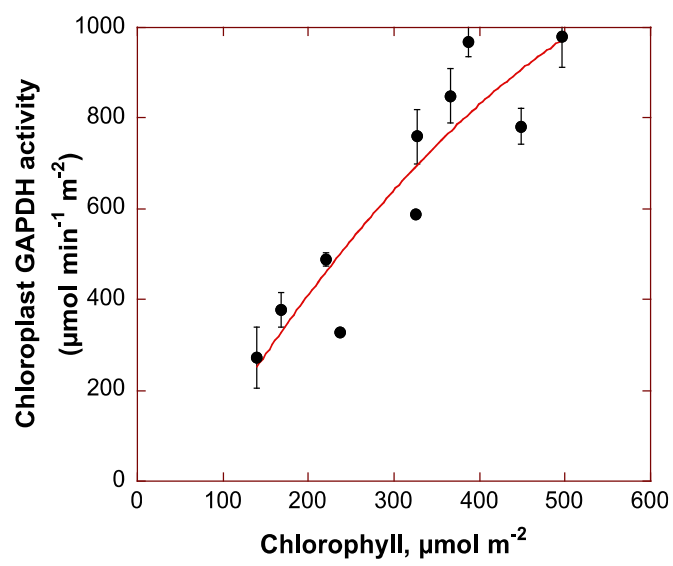

Fig. 2. Relationship between chloroplast GAPDH activity and total chlorophyll content in soybean leaves.

Leaf punches from soybean leaves with varying levels of Chl when assayed for their chloroplast specific GAPDH activity, showed a linear relationship between GAPDH activity and Chl levels ranging from 100 to $500 \mathrm{~mol} \mathrm{~m}^{-2}$ (Fig. 2). As indicated above, $\delta^{13} \mathrm{C}$ values of $\mathrm{C}_{3}$ plants become more negative under conditions that limit their carboxylation capacity. The term "carboxylation capacity" reflects not only the activity of the processes that synthesize RuBP but also the activation state and amount of Rubisco [17], [18]. $\mathrm{CO}_{2}$ assimilation rates inC 3 plants can become limited by RuBP regeneration [19] which depends upon the availability of ATP and NADPH. NADPH-dependent GAPDH is a stromal enzyme that catalyzes the reversible conversion of 3-phosphoglycerate to GAP, using ATP and NADPH. Price [15] demonstrated that the RuBP pool size was linearly related to GAPDH activity in transgenic tobacco engineered with an antisense RNA construct directed against chloroplast specific GAPDH. These antisense plants showed not only reduced activities of GAPDH but also had reduced Rubisco activity, leaf soluble protein and [Chl]. In the present study soybean leaves with varying levels of Chl showed a similar positive correlation between Chl concentration and GAPDH activity (Fig. 2) suggesting an increase in Chl levels tend to increase the RuBP pool size, effecting an enhanced carboxylation capacity.

C. Relationship between Chl and Rubisco Levels

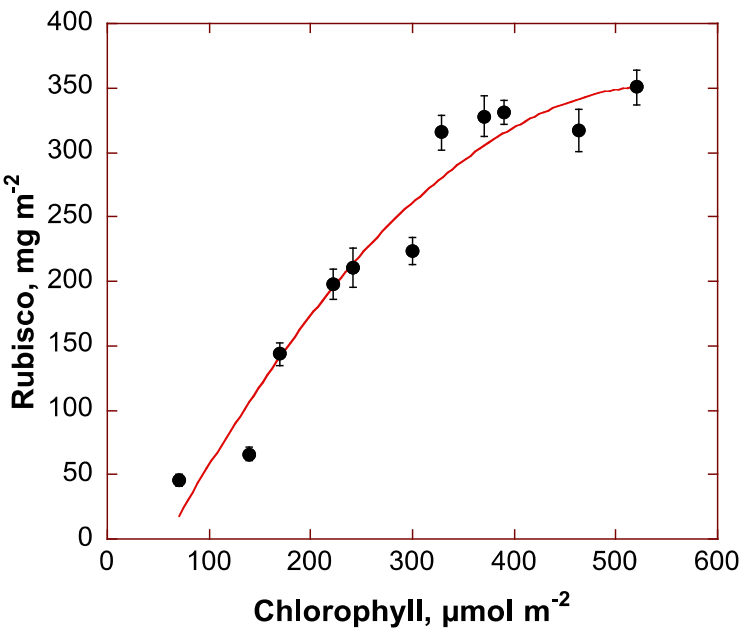

Fig. 3. Correlation between the amount of Rubisco and total chlorophyll concentration in soybean leaves.

Leaf punches from soybean leaves with varying levels of Chl were also assayed for their Rubisco levels. A linear relationship was observed between Rubisco amount and Chl levels ranging from 100 to $500 \mathrm{~mol} \mathrm{~m}^{-2}$ (Fig. 3).

A decreased amount of Rubisco can also cause decreased carboxylation capacity. Transgenic tobacco plants with an antisense gene for the small subunit of Rubisco, not only showed a reduction in Rubisco levels and decreased Rubisco activity [20] but also had reduced Chl levels [21].Carbon isotope analyses of these transgenic plants showed more negative $\delta^{13} \mathrm{C}$ values (by about $3 \%$ ) than the control plants [20]. Rubisco content and carbon isotope discrimination were negatively correlated in groundnut genotypes [6]. A similar significant correlation between leaf [Chl] (from 100 to $350 \mu \mathrm{mol} \mathrm{m}$ ) and rubisco levels is apparent in soybean leaves (Fig.3). The observed, more negative $\delta^{13} \mathrm{C}$ values in these leaves may be due to a decreased carboxylation capacity resulting from decreased Rubisco levels.

\section{Chl Levels and Leaf Photosynthesis}

Increased foliar $\mathrm{Chl}$ concentration accompanied an increased rate of photosynthesis in soybean leaves (Fig. 4). A difference of about $25 \mu \mathrm{mol}$ carbon fixed $\mathrm{m}^{-2} \mathrm{~s}^{-1}$ in net photosynthetic rate was observed in leaves containing 100 to $450 \mu \mathrm{mol} \mathrm{m}-2$ of Chl (Fig. 4).

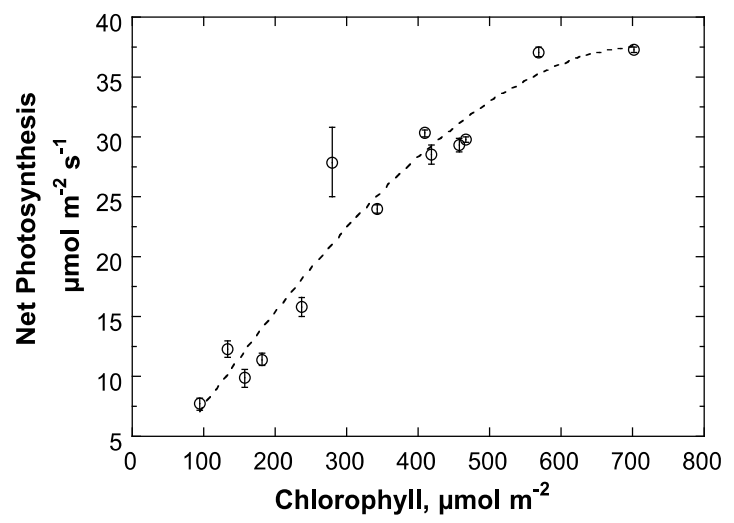

Fig. 4. Effect of varying chlorophyll concentration on net photosynthesis. 
The observed positive relationship between net photosynthetic rate and $\mathrm{Chl}$ levels is consistent with previous reports [9], [23]. Transgenic tobacco plants with antisense genes for GAPDH or the small subunit of Rubisco also showed a linear relationship between total $\mathrm{Chl}$ and net photosynthetic rate [22], [15]. Photosynthetic rate is the product of light absorbed and quantum efficiency of photosynthesis. Results from our study indicate that reduced photosynthetic rate at low Chl levels may be due to a limitation in the rate of supply of photochemical energy. Terry (24) (1983) and Terry and Farquhar (25) (1984) proposed that association between $A$ and $\mathrm{Chl}$ content in sugarbeet was due to colimitation by light-harvesting and electron transport capacity, in addition to limitations due to $\mathrm{CO}_{2}$ diffusion and fixation.

\section{CONCLUSIONS}

Results from this study suggest that chl regulates carbon isotope discrimination in soybean by regulating the carboxylation capacity. The changes that occur with increased levels of $\mathrm{Chl}$ must be significantly larger than the changes that occur in stomata. Foliar $\delta^{13} \mathrm{C}$ values thus appear to effectively communicate this relationship between Chl levels and processes associated with an integrated, long term carbon assimilation in both $\mathrm{C}_{3}$ and $\mathrm{C}_{4}$ plants.

\section{ACKNOWLEDGMENT}

I am grateful to Dr. Jim Specht for providing access to the various lines of soybean in the University of Nebraska nursery plots and to the Late Dr. Wally Wilhelm for the use of his LI-COR 6200 portable photosynthesis system. I also thank Dr. Lowell Moser for his generous gift of rabbit anti-Rubisco antiserum and Sandie Franks and Vern Hansen for their helpful discussions on ELISA. I also thank Jennifer Mitchell and Scott Pinkerton for their help in Chl measurements and field work. This is Journal Series No. 11389 of the University of Nebraska Agricultural Research Division.

\section{REFERENCES}

[1] G. D. Farquhar, J. R. Ehleringer, and K. T. Hubick, "Carbon isotope discrimination and photosynthesis," Ann. Rev. Pl. Physiol. Pl. Mol. Biol. 40, pp 503-537, 1989.

[2] M. H. O'Leary, S. Madhavan, and P. Paneth, "Physical and chemical basis of carbon isotope fractionation in plants," Plant, Cell and Environ, vol. 15, no. 1, pp.1099-1104, 1992.

[3] E. C. Meinzer, G. Goldstein, and D. A. Grantz, "Carbon isotope discrimination in coffee genotypes grown under limited water supply," Plant Physiol, vol. 92, pp. 30-135, 1990.

[4] S. Madhavan, I. Treichel, and M. H. O'Leary, "Effects of Relative Humidity on Carbon Isotope Fractionation in Plants," Bot. Acta, vol. 104, pp. 292-294. 1991.

[5] N. R. C. Rao, M. Udayakumar, G. D. Farquhar, H. S. Talwar, and T. G. Prasad, "Variation in carbon isotope discrimination and its relationship to specific leaf area and ribulose-1, 5-bisphosphate carboxylase content in groundnut genotypes," Aust. J. Pl. Physiol, vol. 22, pp. 545-551, 1995.
[6] M. A. Bevins, S. Madhavan, and J. Markwell, "Two sweetclover (Melilotus albaDesr.) Mutants temperature sensitive for chlorophyll expression," Plant Physiology 103, pp. 1123-1131, 1993.

[7] P. W. Hill, L. L. Handley, and J. A. Raven, “Juniperuscommunis L. ssp. communis at Balnaguard, Scotland: Foliar carbon discrimination (13C) and $15-\mathrm{N}$ Natural abundance $(15 \mathrm{~N})$ suggests gender-linked differences in water and N use," Bot. J. Scotl.48, pp. 209-224, 1996.

[8] I. F. Wardlaw, "The control of carbon partitioning in plants". New Phytol. 116, pp. 341-381, 1990.

[9] S. E. Taylor and N. Terry, "Limiting factors in photosynthesis V. Photochemical energy supply colimits photosynthesis at low values of intercellular $\mathrm{CO}_{2}$ concentration," Plant Physiology, vol. 75, pp. 82-86, 1984.

[10] B. R. Buttery and R. L. Buzzell, "The relationship between chlorophyll content and rate of photosynthesis in soybeans," Can. J. Pl. Sci. vol. 57, pp. 1-5, 1977.

[11] S. L. A. Hobbs and J. D. Mahon, "Inheritance of chlorophyll, ribulose-1,5 bisphosphate carboxylase activity and stomatal resistance in peas. Crop Sci, vol. 25, pp. 1031-1034, 1985.

[12] W. R. Kirchoff, A. E. Hall and M. L. Roose, "Inheritance of a mutation influencing chlorophyll content and composition in cowpea," Crop Sci, vol. 29, pp. 105-108, 1989.

[13] W. T. Pettigrew, J. D. Hesketh, D. B. Peters, and J. T. Wooley, J. T. "Characterization of canopy photosynthesis of chlorophyll-deficient soybean isolines," Crop Sci. vol. 29, pp. 1025-1029, 1989.

[14] J. Markwell, J. C. Ostermanand, and J. L. Mitchell, "Calibration of the Minolta SPAD-502 leaf chlorophyll meter," Photosyn. Res, no. 46, pp. 467-472, 1996.

[15] G. D. Price, J. R. Evans, S. V. Caemmerer, J. W. Yu, and M. R. Badger, "Specific reduction of chloroplast glyceraldehyde-3-phosphate dehydrogenase activity by antisense RNA reduces $\mathrm{CO}_{2}$ assimilation via a reduction in ribulosebisphosphate regeneration in transgenic tobacco plants" Planta, vol. 195, pp. 369-378, 1995.

[16] E. Harlow and D. D. Lane, "Antibodies: A Laboratory Manual", Cold Springs Harbor Laboratory, Cold Springs Harbor, New York, 1988.

[17] G. D. Farquhar and S. V. Caemmerer, "Modeling of photosynthetic response to environmental conditions," In: Physiological Plant Ecology II: Water relations and carbon assimilation. (eds. Lange OL, Nobel PS, Osmond CB and Ziegler H) vol. 12B, pp 549-587, Springer Verlag, Berlin, 1982.

[18] G. D. Farquhar, "Models describing the kinetics of RuBP carboxylase-oxygenase," Arch. Biochem.Biophys, vol. 193, pp. 456-468, 1979.

[19] D. R. Geiger and J. C. Servaites, "Dynamics of self regulation of photosynthetic carbon metabolism," Pl. Physiol. Biochem, vol. 32, pp. 173-183, 1994.

[20] G. S. Hudson, J. R. Evans, J. R., S. V. Caemmerer, Y. B. C. Arvidsson and T. J. Andrews, T. J. "Reduction of ribulose-1,5-bisphosphate carboxylase/oxygenase content by antisense RNA reduces photosynthesis in transgenic tobacco plants," Pl. Physiology, vol. 98, pp. 294-302, 1992.

[21] W. P. Quick, U. Schurr, R. Scheibe, E. D. Schulze, S. R. Rodermel, L. Bogorad, and M. Stitt, "Decreased ribulose-1,5-bisphosphate carboxylase-oxygenase in transgenic tobacco transformed with "antisense" rbcS. Planta, vol. 183, pp. 542-554, 1991.

[22] M. Stitt, W. P. Quick, U. Schurr, E. D. Schulze, S. R. Rodermal, and L. Bogorad "Decreased ribulose-1,5-bisphosphate carboxylase-oxygenase in transgenic tobacco transformed with "antisense" rbcS. II Flux-control coefficients for photosynthesis in varying light, $\mathrm{CO}_{2}$ and air humidity," Planta, vol. 183, pp. 555-566, 1991.

[23] B. L. Ma, M. J. Morrison and H. D. Voldeng, "Leaf greenness and photosynthetic rates in soybean," Crop Sci, vol. 35, pp. 1411-1414, 1995.

[24] N. Terry, "Limiting Factors in Photosynthesis. IV Iron stress-mediated changes in light harvesting and electron capacity and its effect on photosynthesis in vivo," Plant Physiol, vol. 71, pp 855-860, 1983.

[25] N. Terry and G. D. Farquhar, "Photochemical capacity and photosynthesis. In Control of Crop Productivity," in Control of crop productivity, C. J. Pearson, Ed. Academic Press, Sydney, Australia, pp 43-57, 1984. 